\title{
Optimal laptop VDU parameter setting using Taguchi method
}

\author{
Anshul Gangele ${ }^{\mathrm{a}}$ and Ajay Mishra ${ }^{\mathrm{b} *}$
}

${ }^{a}$ Professor, Department of Mechanical \& Automation Engg., Amity University, Gwalior, India ${ }^{b}$ Research Scholar, Department of Mechanical Engg., Suresh Gyan Vihar University, Jaipur, India

\section{H R O N I C L E}

\begin{tabular}{l}
\hline Article history: \\
Received March 25, 2015 \\
Received in revised format June \\
102015 \\
Accepted July 282015 \\
Available online \\
August 22015 \\
\hline Keywords: \\
VDU parameter setting \\
Laptop \\
Taguchi method
\end{tabular}

\section{Introduction}

In today's era computers have become a necessary requirement in the office workplace and their use is growing continuously in almost each and every field. Because of their portability and convenience, laptops are becoming widely used and replaces the desktop personal computers. People use laptops for various tasks and reading is one of the most important tasks among them during record management, document preparation, data exchanging, electronic communications, chatting, net surfing etc. That's why visual display unit (VDU) of laptops plays a very important role in this regard. According to Timmers et al. (1980), readability of printed or typed text and its comprehension is a function of a wide assortment of factors, such as font style, type form (capital, lowercase, boldface, italics, etc.), font size, contrast, line spacing, length of line, and margins. Soleimani (2012) investigated the relationships among font type, font size, and line spacing and legibility by measuring speed of reading, comprehension, and recalling. Instruments for testing legibility and reading comprehension were presented in eight typographical styles in print. Results indicated that the 12pt was reading faster than

* Corresponding author. Tel: +91-9827434208

E-mail address: ajay_mishra552000@rediffmail.com (A. Mishra) 
10pt. But font selection and line spacing did not have any significant effect on reading speed. Also, there were no significant results with regard to comprehension and recalling. Silver and Braun's (1993) examination on the effect of type size on readability of warnings of the drugs supports Delamater's (2010) idea. They used 8 and 10 point sizes and concluded from their study that the warning printed in 10 point type was perceived more readable than 8 point type was. Silver and Braun (1993) studied on warning readability on the labeling of various consumer products and reported that Helvetica type was perceived to be more readable than Times or Goudy. Moreover, the Times was perceived to be more readable than Goudy.

Saito et al. (1997) evaluated working conditions using a personal computer with a flat panel display (FPD) in terms of visual and musculoskeletal comfort. Measurements of viewing distance, viewing angle, head angle, neck angle and electromyogram (EMG) activities of the neck, shoulder and back muscles of visual display terminal (VDT) operators were compared at workstations using an FPD and a desktop personal computer (DPC). Results show that to prevent visual and musculoskeletal problems using NPCs, a more upright head and neck position must be carefully considered. The addition of a mechanism for adjustment of the height of an NPC display would allow a comfortable downward gaze without the loss of correct posture.

Szeto and Lee (2002) evaluated and compared the postures and movements of the cervical and upper thoracic spine, the typing performance, and workstation ergonomic factors when using a desktop, notebook, and subnotebook computers. They found that computer users need to consider the posture of the spine and potential risk of developing musculoskeletal discomfort in choosing computers. Bayumi et al. (2013) presented a study which aims at determining the optimum level of five parameters, namely font size, font style, line spacing, text/background color combination, and viewing distance that might improve operator's performance of readability tasks on computers and avoid physical stress. Four levels of each parameter were considered. Taguchi method which applies Robust Design and Orthogonal Array was used because of its inherent quality of time and cost savings in experimentation. An experimental setup was prepared in which the standard values of three other variables viz. table height, inclination angle, and illumination were fixed. Based on the experimental data and Taguchi method analysis of variance (ANOVA) is undertaken which determines the process parameter most contributing to optimal levels.

In a study by Ling and Schaik (2007), the effects of text presentation on online behavior and preferences in order to generate design guidelines for the production of web pages was investigated and found that text presentation had a significant effect on task performance, with wider line spacing leading to better accuracy and to faster reaction times. Mocci et al. (2001) examined the part played by psychological factors in complaints about visual health reported by banking officers who work at video display terminals (VDTs). Results show that some part of the complaints about visual health reported by VDT workers were likely indirect expressions of psychological discomfort related to working conditions.

Although different typefaces or fonts have different connotations and can have an influence on the readability, interpretation, and the impact of the words they represent (Thangaraji, 2004), for decades, there has been a disagreement among the scientists and typographers concerning the best typographical factors using in print. Because fonts give form to the written word, they speak to people. People always appreciate the fonts they like and complain the ones that they don't like, but they have to use (Friedman, 2009). Geske (1996) conducted a study to find out which point size is suitable for on-screen reading. He used 9, 10, and 12 point sizes in Helvetica but results did not indicate any significant differences. Bernard, Chaparro, Mills, and Halcomb's (2010) finding are similar to that of Geske (1996).Subbaram's (2004) finding is against Geske's (1996) and his supporters. In his study, the largest font which was 14- point size was proven to be more legible. On the basis of above literature survey, researchers have decided to use five factors, each at three levels which are font size, font style, line spacing, viewing distance and screen inclination angle with reading time in seconds (for reading about 
300 words) as the response variable. Other parameters like text/background color combination (black/white), table height, illumination etc. were kept constant.

\section{Objective of the study}

The main objective the study is to determine optimum levels of five selected process parameters, namely font size, font style, line spacing, viewing distance $(\mathrm{cm})$ and screen inclination angle (degrees) that could maximize the readability of the user through a set of experiments with the help of Taguchi method, orthogonal array and analysis of variance. Here reading time in seconds (for reading about 300 words) was used as the response variable. These five factors and their levels are shown in Table 1.

Table 1

Factors and their Levels

\begin{tabular}{llllll}
\hline No. & Factors & Code & \multicolumn{2}{c}{ Levels } & \\
\hline 1. & Font size & A & 10 & 12 & 14 \\
2. & Font Style & B & Times New Roman & Arial & Callibari \\
3. & Line Spacing & C & 1 & 1.5 & 2 \\
4. & Viewing Distance(d) & D & 33 & 47 & 60 \\
5. & Screen Inclination Angle $(\theta)$ & E & 100 & 105 & 110 \\
\hline
\end{tabular}

\section{Experimental setup and equipment requited}

Since in this study, five parameters each at three levels have been selected, therefore L27 orthogonal array have been used for better results. So, the experiments were conducted by varying different parameters on the basis of L27 orthogonal array design. To perform these experiments, a sample of three users has been used, i.e. each user has been used nine times randomly one by one. Out of these three users, one was female and the two others were male. Average age of users was 30.33 years and the average height was $178.79 \mathrm{~cm}$. The users were familiar and comfortable in reading English and the same article was used for all the 27 experiments. Finally, the equipment required for the experiments are VDU (laptop), table, adjustable chair, measuring tape and stop watch. L27 orthogonal array with responses are shown in Table 2 and Fig. 1 shows the experimental set up for the study. Since the response variable is reading time in seconds which is smaller the better type, so "Smaller the Better" type signal to noise ratio was used which is given by the following equation:

$\mathrm{S} / \mathrm{N}=-10 \log \left[\sum_{i=0}^{n} \frac{Y_{i}^{2}}{n}\right]$

Here, $n$ represents the number of observations and $\mathrm{Y}_{1}, \mathrm{Y}_{2}, \mathrm{Y}_{3}$, $Y_{n}$ represent the values of a performance characteristics. Pareto chart for these $\mathrm{S} / \mathrm{N}$ ratios are shown in the Fig. 2.

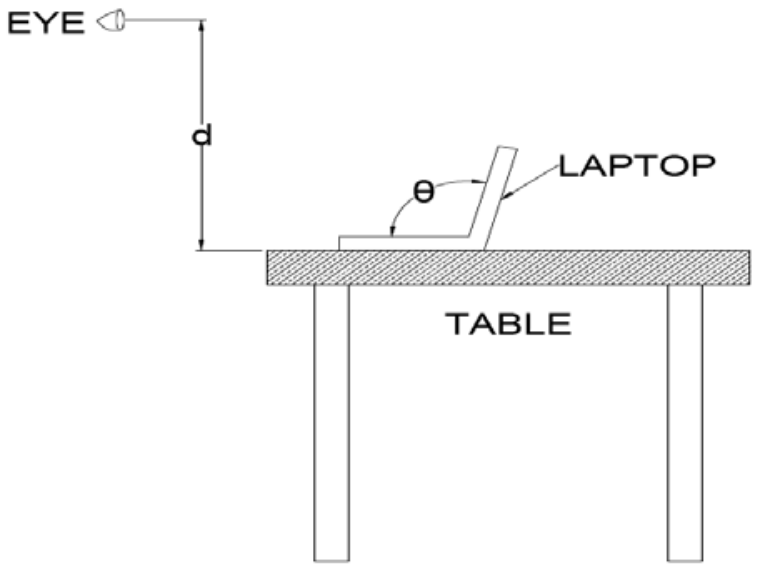

Fig. 1. Arrangement for Experimental Set-up 
Table 2

$\mathrm{L}_{27}$ Orthogonal array for experiments with responses and $\mathrm{S} / \mathrm{N}$ ratios

\begin{tabular}{|c|c|c|c|c|c|c|c|}
\hline Sr. No. & $\mathrm{A}$ & B & $\mathrm{C}$ & $\mathrm{D}$ & $\mathrm{E}$ & $\mathrm{Y}$ & S/N Ratios \\
\hline 1 & 1 & 1 & 1 & 1 & 1 & 110 & -40.8279 \\
\hline 2 & 1 & 1 & 1 & 1 & 2 & 108 & -40.6685 \\
\hline 3 & 1 & 1 & 1 & 1 & 3 & 107 & -40.5877 \\
\hline 4 & 1 & 2 & 2 & 2 & 1 & 98 & -39.8245 \\
\hline 5 & 1 & 2 & 2 & 2 & 2 & 96 & -39.6454 \\
\hline 6 & 1 & 2 & 2 & 2 & 3 & 95 & -39.5545 \\
\hline 7 & 1 & 3 & 3 & 3 & 1 & 102 & -40.1720 \\
\hline 8 & 1 & 3 & 3 & 3 & 2 & 108 & -40.6685 \\
\hline 9 & 1 & 3 & 3 & 3 & 3 & 112 & -40.9844 \\
\hline 10 & 2 & 1 & 2 & 3 & 1 & 101 & -40.0864 \\
\hline 11 & 2 & 1 & 2 & 3 & 2 & 95 & -39.5545 \\
\hline 12 & 2 & 1 & 2 & 3 & 3 & 96 & -39.6454 \\
\hline 13 & 2 & 2 & 3 & 1 & 1 & 104 & -40.3407 \\
\hline 14 & 2 & 2 & 3 & 1 & 2 & 102 & -40.1720 \\
\hline 15 & 2 & 2 & 3 & 1 & 3 & 106 & -40.5061 \\
\hline 16 & 2 & 3 & 1 & 2 & 1 & 104 & -40.3407 \\
\hline 17 & 2 & 3 & 1 & 2 & 2 & 98 & -39.8245 \\
\hline 18 & 2 & 3 & 1 & 2 & 3 & 108 & -40.6685 \\
\hline 19 & 3 & 1 & 3 & 2 & 1 & 102 & -40.1720 \\
\hline 20 & 3 & 1 & 3 & 2 & 2 & 92 & -39.2758 \\
\hline 21 & 3 & 1 & 3 & 2 & 3 & 94 & -39.4626 \\
\hline 22 & 3 & 2 & 1 & 3 & 1 & 97 & -39.7354 \\
\hline 23 & 3 & 2 & 1 & 3 & 2 & 91 & -39.1808 \\
\hline 24 & 3 & 2 & 1 & 3 & 3 & 95 & -39.5545 \\
\hline 25 & 3 & 3 & 2 & 1 & 1 & 94 & -39.4626 \\
\hline 26 & 3 & 3 & 2 & 1 & 2 & 90 & -39.0849 \\
\hline 27 & 3 & 3 & 2 & 1 & 3 & 98 & -39.8245 \\
\hline
\end{tabular}

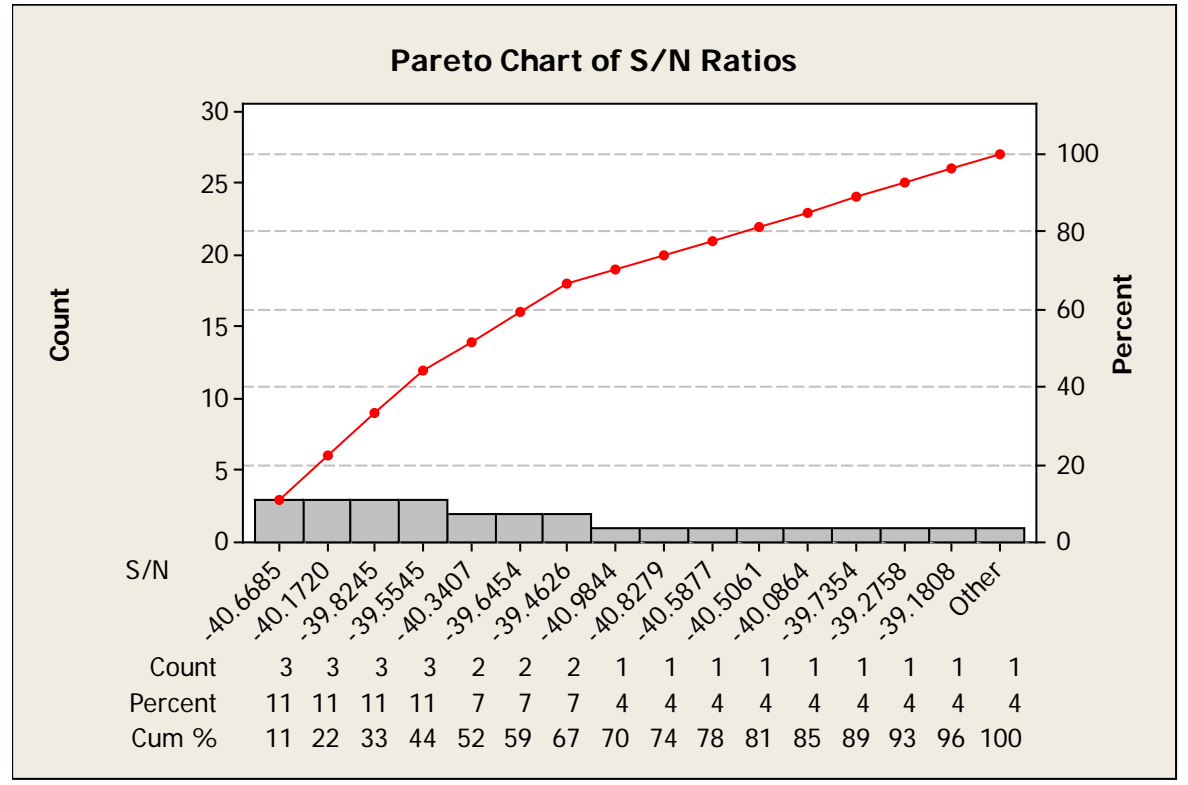

Fig. 2. Pareto Chart of S/N Ratios

\section{Results, analysis and discussions}

The response variable which is reading time and corresponding signal to noise ratios are shown in Table 2 and their Pareto chart is shown in Fig. 2. On the basis of these data, mean responses for each factor and their corresponding levels are shown in Table 3 and Table 4. Here, Table 3 represents the response table for means and Table 4 represents the response table for signal to noise ratios. These tables clearly 
indicate the ranking of the factors which shows their relative importance. According to these tables, factor A (font size) is the most important factor which is font size followed by factor $C$ (line spacing), factor $\mathrm{E}$ (screen inclination angle), factor D (viewing distance) and factor B (the font style) which is the least important factor. In determining the percentage contribution of each factor analysis of variance was performed both for the means and signal to noise ratios. The percentage contribution obtained by analysis of variance for means are $40.65 \%$ for factor A (font size), $5.21 \%$ for factor B (the font style), $23.9 \%$ for factor C (line spacing), $5.89 \%$ for factor D (viewing distance) and $7.28 \%$ for factor $\mathrm{E}$ (screen inclination angle). Approximately same results are obtained by analysis of variance signal to noise ratios which are $41.14 \%$ for factor A (font size), $4.92 \%$ for factor B (the font style), $23.56 \%$ for factor C (line spacing), $5.68 \%$ for factor D (viewing distance) and $7.72 \%$ for factor $\mathrm{E}$ (screen inclination angle).These tables also verifies the results obtained by the response table for means and signal to noise ratios.

\section{Table 3}

Response Table for Means

\begin{tabular}{lccccc}
\hline Level & $\mathrm{A}$ & $\mathrm{B}$ & $\mathrm{C}$ & $\mathrm{D}$ & $\mathrm{E}$ \\
\hline 1 & 104.00 & 100.56 & 102.11 & 102.11 & 101.33 \\
2 & 101.56 & 98.22 & 95.89 & 98.56 & 97.78 \\
3 & 94.78 & 101.56 & 102.44 & 99.67 & 101.22 \\
Delta & 9.22 & 3.33 & 6.56 & 3.56 & 3.56 \\
Rank & 1 & 5 & 2 & 3.5 & 3.5 \\
\hline
\end{tabular}

\section{Table 4}

Response Table for S/N Ratios

\begin{tabular}{lccccc}
\hline Level & A & B & C & D & E \\
\hline 1 & -40.33 & -40.03 & -40.15 & -40.16 & -40.11 \\
2 & -40.13 & -39.83 & -39.63 & -39.86 & -39.79 \\
3 & -39.53 & -40.11 & -40.19 & -39.95 & -40.09 \\
Delta & 0.80 & 0.28 & 0.56 & 0.30 & 0.32 \\
Rank & 1 & 5 & 2 & 4 & 3 \\
\hline
\end{tabular}

\section{Table 5}

Analysis of variance for Means

\begin{tabular}{lrrrrrrr}
\hline Source & DF & Seq SS & Adj SS & Adj MS & \multicolumn{1}{c}{ F } & P & \% Contribution \\
\hline A & 2 & 410.89 & 410.89 & 205.44 & 19.06 & 0.000 & 40.65 \\
B & 2 & 52.67 & 52.67 & 26.33 & 2.44 & 0.119 & 5.21 \\
C & 2 & 241.56 & 241.56 & 120.78 & 11.21 & 0.001 & 23.90 \\
D & 2 & 59.56 & 59.56 & 29.78 & 2.76 & 0.093 & 5.89 \\
E & 2 & 73.56 & 73.56 & 36.78 & 3.41 & 0.058 & 7.28 \\
\hline Residual Error & 16 & 172.44 & 172.44 & 10.78 & & & \\
Total & 26 & 1010.67 & & & & & \\
\hline
\end{tabular}

\section{Table 6}

Analysis of variance for S/N Ratios

\begin{tabular}{lccccccc}
\hline Source & DF & Seq SS & Adj SS & Adj MS & F & P & \%Contribution \\
\hline A & 2 & 3.1031 & 3.1031 & 1.55154 & 19.38 & 0.000 & 41.14 \\
B & 2 & 0.3710 & 0.3710 & 0.18548 & 2.32 & 0.131 & 4.92 \\
C & 2 & 1.7776 & 1.7776 & 0.88880 & 11.10 & 0.001 & 23.56 \\
D & 2 & 0.4285 & 0.4285 & 0.21424 & 2.68 & 0.099 & 5.68 \\
E & 2 & 0.5825 & 0.5825 & 0.29127 & 3.64 & 0.050 & 7.72 \\
Residual Error & 16 & 1.2810 & 1.2810 & 0.08006 & & & \\
Total & 26 & 7.5437 & & & & & \\
\hline
\end{tabular}


On the basis of response table for means and response table for signal to noise ratios, main effects plots for means (Fig. 3) and main effects plots for signal to noise ratios (Fig. 4) have been plotted which clearly indicates the results obtained from response tables and analysis of variance. These plots show the optimum level of design parameters which are A3B2C2D2E2 that means Font size is 14, Font Style is Arial, Line Spacing 1.5, Viewing Distance 47 cm., Screen Inclination Angle 105 .

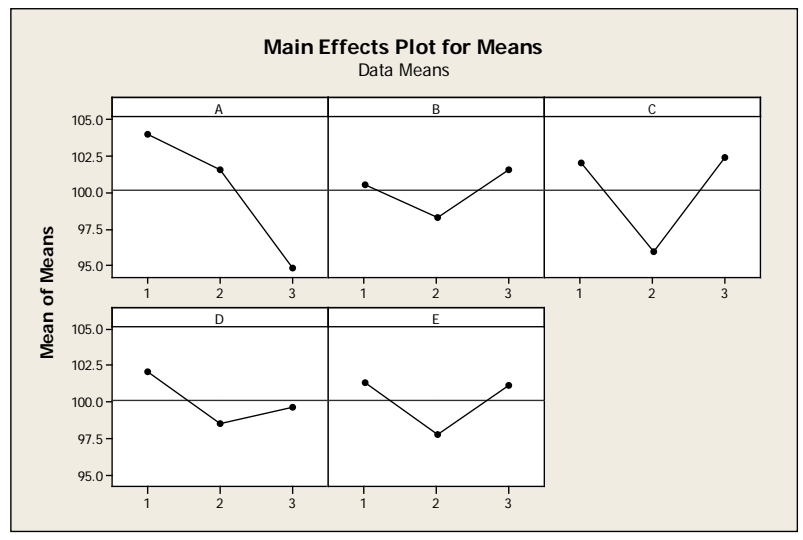

Fig. 3. Main Effects Plot for Means

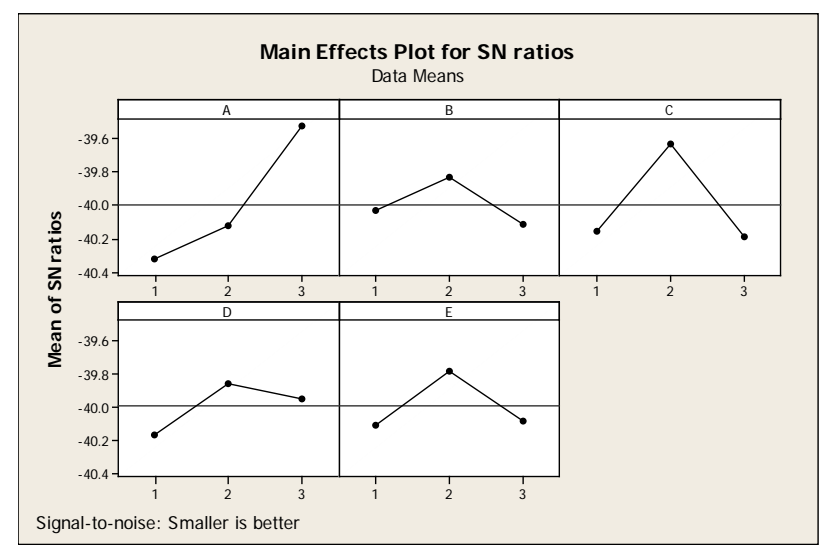

Fig. 4. Main Effects Plot for SN ratios

Lastly, analytic examination has been performed through the normal probability plot for the present study, which is shown in the Fig. 5. The residuals are usually falling on a straight line shows that errors are normally distributed. From the Fig. 5, the conclusion can be drawn that all the values are coming inside the confidence interval of $95 \%$, therefore these values gives better results in the future prediction within the limits. The adequacy of the model represented in this paper was verified by using the normal probability plot of the residuals, as shown in Fig. 5. The points are very close to the normal probability line; thus, there is convincing evidence that the model is adequate. Thus, the model formulated for the prediction of optimizing the VDU parameters for maximizing the readability on a laptop, is adequate.

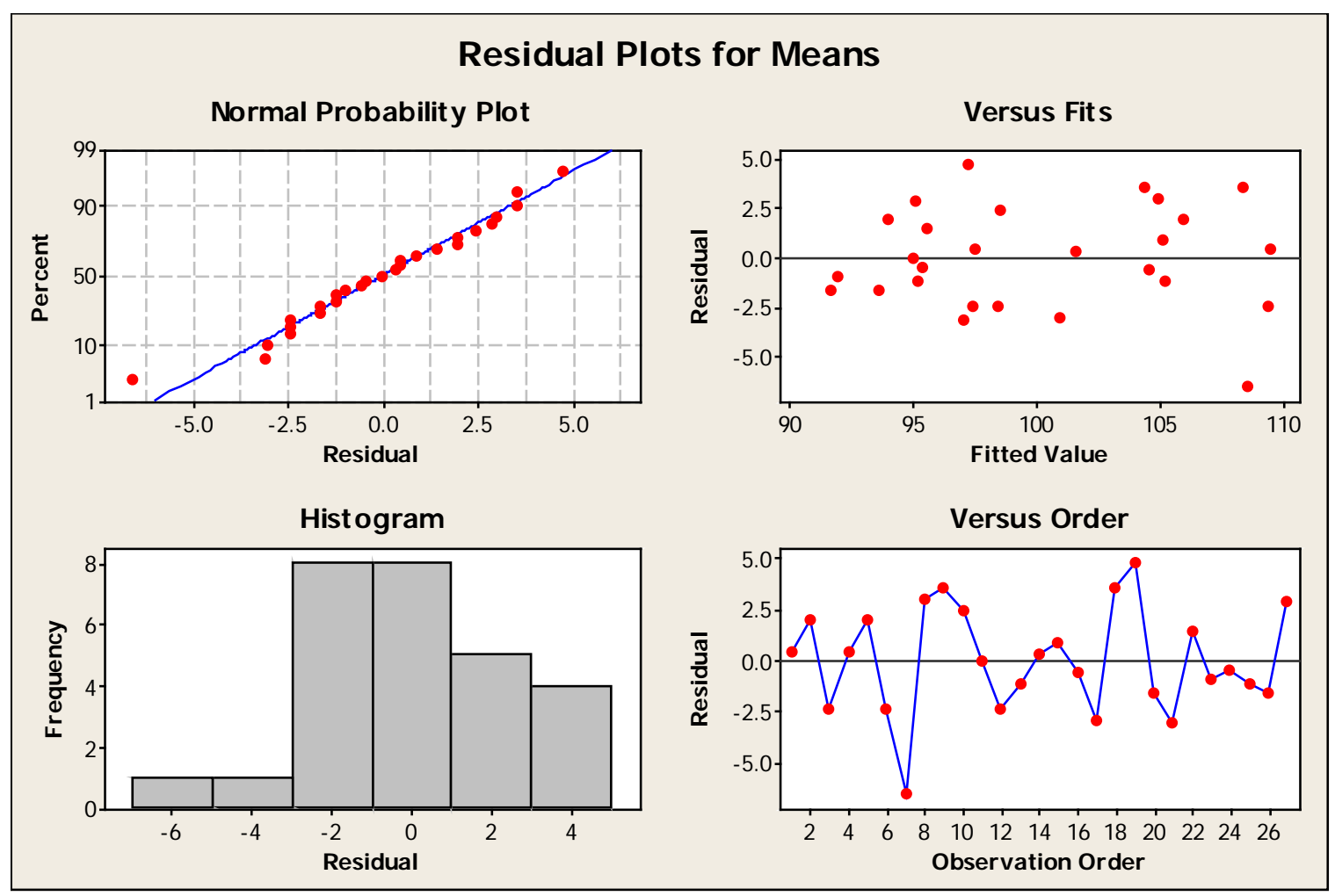

Fig. 5. Residual Plots for Means 


\section{Estimation of predicted response at optimal condition}

The optimal value of reading time is predicted at the selected level of factors which are A3, B2, C2, D2 and E2.The estimated mean reading time at optimal condition can be calculated as:

$\mathrm{Y}_{\text {Predicted }}=\mathrm{A} 3+\mathrm{B} 2+\mathrm{C} 2+\mathrm{D} 2+\mathrm{E} 2-4 \mathrm{Y}_{\text {Mean }}$

where, $Y_{\text {Predicted }}=$ Predicted mean reading time

$$
\begin{aligned}
& \text { A3 }=94.78 \\
& \text { B2 }=98.22 \\
& \text { C2 }=95.89 \\
& \text { D2 }=98.56 \\
& \text { E2 }=97.78 \\
& Y_{\text {Mean }}=\text { Overall mean reading time }=100.11
\end{aligned}
$$

Therefore, Y Predicted $=84.79$ seconds

So, the predicted mean response shows that there is a $15.3 \%$ decrease in mean reading time when working at optimal condition. Three confirmation experimental runs were conducted at the selected optimum settings of machining process parameters. In this confirmation experiments the average reading time was found to be 87 seconds. This result is very much close to the predicted value and this confirmation run results verify the effectiveness of the study.

\section{Conclusion}

This paper shows that the Taguchi method of optimization can be easily used in optimizing the VDU parameters for maximizing the readability on the laptop. The results show that the optimum level of design parameters are A3B2C2D2E2 that means Font size is 14, Font Style is Arial, Line Spacing 1.5, Viewing Distance $47 \mathrm{~cm}$., Screen Inclination Angle 105\%. ANOVA table for means shows the percentage contribution of each factor which are $40.65 \%$ for font size, $5.21 \%$ for font style, $23.90 \%$ for line spacing, $5.89 \%$ for viewing distance and $7.28 \%$ for inclination angle. These results are verified by ANOVA table for $\mathrm{S} / \mathrm{N}$ ratios which shows approximately same results. That means factor $\mathrm{A}$ is the most important factor which is font size followed by factor $\mathrm{C}$ (line spacing), factor $\mathrm{E}$ (screen inclination angle), factor D (viewing distance) and factor B (font style) which is the least important factor.

\section{References}

Bayumi A., Shewakh W.M., \& Haleem A. (2013). Design optimal VDU parameters for the readability task to alleviate posture discomfort mental stressors. International Journal of Industrial engineering and technology, 3(2), 53-66.

Bernard, M. L., Chaparro, B. S., Mills, M. M., \& Halcomb, C. C. (2002). Examining children’s reading performance and preference for different computer- display text. Behavour \& Information Technology, 21(2), 87-96.

Delamater, W. E. (2010). How larger font size impacts reading and the implications for educational use of digital text readers. eReadia, April 29, 2010.

Friedman, J. J. (2009). A note on the type Font designers imagine a better-looking web. Technology Review.

Geske, J. (1996). Legibility of sans serif type for use as body copy in computer mediated communication. Retrieved from Eric data base. (ED399 590)

Ling, J., \& Schaik, P.V. (2007). The influence of line spacing and text alignment on visual search of web pages. Displays, 28(2), 60-67. 
Mitra, A. (2000), Fundamentals of Quality Control and Improvement, Pearson Prentice Hall, U.S.A.

Mocci, F., Serra, A., \& Corrias, G. A. (2001). Psychological factors and visual fatigue in working with video display terminals. Occupational and Environmental Medicine, 58(4), 267-271.

Phadke, S. M. (1989). Quality Engineering Using Robust Design. Prentice Hall, Eaglewood Cliffs, New Jersey.

Roy, R. K. (1990). A Primer on the Taguchi Method. Van Nostrand \& Reinhold, United States of America.

Saito, S., Miyao, M., Kondo, T., Sakakibara, H., \& Toyoshima, H. (1997). Ergonomic evaluation of working posture of VDT operation using personal computer with flat panel display. Industrial health, 35(2), 264-270.

Silver, N. C., \& Braun, C. C. (1993). Perceived readability of warning labels with varied font sizes and styles. Safety Science, 16(5), 615-625.

Soleimani H. (2012). On the relationship between font size, font type, and line spacing and legibility, comprehension, and recall of EFL learners in Iran. Science Series Data Report, 4(5), 13-31.

Subbaram, V. M. (2004). Effect of display and text parameters on reading performance (Doctoral dissertation), The Ohio State University, 2004, Physiological Optics.

Szeto, G. P., \& Lee, R. (2002). An ergonomic evaluation comparing desktop, notebook, and subnotebook computers. Archives of physical medicine and rehabilitation, 83(4), 527-532.

Thangaraj, J. (2004). Fascinating fonts; is the power of typography a marketing myth. Style DeKalb IL, 2(1), 1-7.

Timmers, H., Van-Nes, F.L., \& Ballomeart, F.J.J. (1980). Visual word recognition as a function of contrast, ergonomics of VCT. Proceeding of the International Workshop, 115-120. 